\title{
The Complaint Response Strategies in the Airline Outbound Calls from the Perspective of Rapport Management
}

\author{
Honglin Yang ${ }^{1} \&$ Ping Liu ${ }^{1}$ \\ ${ }^{1}$ School of English for International Business, Guangdong University of Foreign Studies, Guangzhou, China \\ Correspondence: Ping Liu, School of English for International Business, Guangdong University of Foreign Studies, \\ No.2 Baiyundadaobei, Guangzhou 510420, P.R.China. Tel: 0086-150-1309-5022. E-mail: 200110438@ \\ oamail.gdufs.edu.cn
}

Received: October 15, 2020; Accepted: October 29, 2020; Published: October 30, 2020

This study has been supported by the project (18SS04) "The Pragmatic Effects and Strategies of the Complaint Response Utterances of Business Institutions", funded by Guangdong University of Foreign Studies, China.

\begin{abstract}
Customer complaints can have a significant influence on the rapport and relationships between the customer and the company. This article aims to study the company's response strategies for customer complaints from the perspective of rapport management, collecting the data from the airline outbound calls. Results show that there are three types of customer complaints and three kinds of response strategies related, but the effect of strategies on rapport management is not satisfying.
\end{abstract}

Keywords: customer complaints, response strategies, airline outbound calls, rapport management

\section{Introduction}

With the rapid development of the society and economy, people live a better life but also suffer more daily stress. The most convenient way of relieving the stress is to make complaints. A student can complain about the burdensome homework to the classmates, an office worker may complain about the fussy boss to the fellows, and a customer can complain about the bad service to the agents. The last one is much more important in the business setting. Customer complaints can reflect the existing or potential problems in the products or services, influence the desire and decisions of other buyers, and impair the image and word-of-mouth of a company. Therefore, a company must treat the complaints carefully and respond to them effectively in a timely manner.

From this point of view, the authors want to study the company's strategies in response to customer complaints, trying to find out how and how well the company would maintain the rapport and relationship with customers. The previous related researches collected their data mainly from the computer-mediated communication (CMC) in the hotel industry (e.g., Zhang \& Vásquez, 2014; Sparks \& Bradley, 2017; Ho, 2017a, 2017b, 2018), but this article will concentrate on the customer hotline service in the airline industry, and use the first-hand data mainly from the recordings of outbound calls to customers.

\section{Rapport and Rapport Management}

Given that this article is theoretically based on rapport management, the keyword "rapport" needs to be clearly defined first. According to Spencer-Oatey (2008), the relationship between companies and customers is changeable and subtle, which can be measured by rapport. Rapport is modified and evolved from the concept of face and politeness. The term "face" was first established by the American sociologist Erving Goffman (1955: 213), who thought "face is the positive social value a person effectively claims for himself by the line others assume he has taken during a personal contact". Then, Brown \& Levinson (1987) developed Goffman's face theory into another influential theory in the field of pragmatics, politeness theory. In this theory, face contains two aspects, positive face and negative face. The former is about an individual's desire to be approved of, while the latter concerns one's desire to be unimpeded. To save the positive face, positive politeness strategies are raised to avoid offence by highlighting friendliness; to save the negative face, negative politeness strategies are applied to avoid offence through deference (Brown \& Levinson, 1987).

Taking the above ideas into account, Spencer-Oatey (2008) proposed a modified and expanded framework conceptualizing rapport. She constructed rapport as "people's subjective perceptions of (dis)harmony or 
smoothness-turbulence in interpersonal relations" (2008, 335), and also defined rapport management as "the management of harmony-disharmony among people" (2008, 13). Rapport management entailed three main interconnected components: the management of face, sociality rights and obligations, and interactional goals. Details are shown in the following Table 1.

Table 1. Components of rapport management

\begin{tabular}{|c|c|}
\hline Components & Definition \\
\hline Face & $\begin{array}{l}\text { Participants' sense of worth, dignity and identity, related to issues like respect, } \\
\text { honor and reputation }\end{array}$ \\
\hline Sociality rights and obligations & $\begin{array}{l}\text { People's social expectancies over fairness, consideration and behavioral } \\
\text { appropriateness; } \\
\text { Two subcategories of equity and association rights; } \\
\text { Equity rights: fair treatment instead of forcement, order or exploitation; } \\
\text { Association rights: moderate social involvement with others }\end{array}$ \\
\hline Interactional goals & $\begin{array}{l}\text { Participants' specific goals (transactional or/and relational) in interaction with } \\
\text { each other }\end{array}$ \\
\hline
\end{tabular}

However, rapport among people is not always dealt with well and may be threatened sometimes, so Spencer-Oatey elicited the rapport-threatening behavior from the three perspectives of face, sociality rights and obligations and interactional goals. To handle such behavior, people need to use strategies to make it up and manage rapport again. Spencer-Oatey (2008) suggested, people's strategy use would be influenced by their rapport orientation, including rapport enhancement, maintenance, neglect and challenge. Rapport enhancement focuses on the positive change, that is, the relation improvement between people. The aim of rapport maintenance is to preserve the current quality of relationship or to minimize the aftermath of rapport-threatening behavior. And in the rapport neglect orientation, people usually show little care or concern for the quality of relationship among them. Finally, those holding rapport challenge orientation, wittingly or not, impair the relationship and worsen the rapport.

Apart from rapport orientation, contextual variables are also the important factors influencing strategy use in managing rapport (Spencer-Oatey, 2008, 33-42). Contextual variables include participant relations, message content, social/interactional roles and activity type. First, power and distance are regarded as the key variables relating to participant relations. Second, any message can have "costs" and "benefits" associated with it, in terms of time, effort, convenience, finance, etc. The greater costs or benefits will lead to the greater imbalance between the relationship, so strategies are required to restore the equilibrium. Third, the role relationships of social interaction can specify the rights and obligations of each role member. For example, an employer has an obligation to handle management issues, while he/she also gets a right to expect the employees to comply with the directives and finish the tasks. Finally, different types of communicative activities, like a chat, a lecture or an interview, may employ different rapport management strategies.

Under the business background, customer complaints are actually a signal of damaged relationship, and before managing them, a company must figure out what aspects of relationship or rapport have been influenced. This article collects its data from the telephone calls, where the customer complaints will be first located and generated based on the three perspectives of rapport-threatening behavior. In the discussion above, the four rapport orientations influence people's purpose of strategy use, normally emphasizing on why they choose a certain strategy. Instead, in this article, the orientations will be adopted to evaluate the effect of the agents' response strategies on rapport management, paying attention to how well they are used.

\section{Customer Complaints}

In the business setting, complaints always link to another term "customer complaint behavior" (CCB). Singh \& Widing (1991) thought CCB was to deal with the identification and evaluation of all aspects involved in the customer's reaction to service failure and consequent dissatisfaction. According to Phau \& Puspita Sari (2004), CCB involved the customer's negative reaction to dissatisfaction derived from a low quality of products or services Generally speaking, customer complaints refer to those negative comments about consumed products or services, but in this article, they will be specially defined as the customers' remarks involving rapport-threatening behavior. As the Internet gradually prevails in every corner of the world, the computer-mediated communication (CMC) is penetrating into people's daily life. Javornik et al. $(2020,101)$ believed that "the advent of social media has led to consumers more frequently voicing their complaints online". Then it's more necessary in the online environment 
to manage customer complaints, which will widely influence the company's word-of-mouth and the relationship with existing and potential customers. According to Lee \& Song $(2010,1079)$, "appropriate response strategies could engender the consumer's positive attitude towards the negative events". In this research, they adopted three general types of response strategies: accommodative strategies, which encompasses any form of apology, compensation, and/or corrective action; defensive strategies, including any form of denial, attack, or shifting blame to others; "no action" strategies, referring to non-substantive comment or non-overt action. After the experiments and analyses, it was demonstrated that "accommodative strategies may provide favorable outcomes toward the negative events, including consumers' satisfaction and their continued loyalty to the company" (Lee \& Song, 2010, 1079). On the other hand, Van Noort \& Willemsen (2012) drew upon a reactive-proactive distinction of webcare strategies based upon the interaction dynamics of the response. These two scholars defined webcare as "the act of engaging in online interactions with (complaining) consumers, by actively searching the web to address consumer feedback" $(2012,133)$. A proactive webcare strategy is to take on a proactive approach and respond unsolicitedly to customer complaints. But with a reactive webcare strategy, a company will give responses only when it is explicitly asked to do so by customers.

In the tourism and hospitality fields, more specific response strategies for online customer complaints have been concluded from the data as follows. After exploring 225 management responses from 86 Washington, D.C. hotels, Levy et al. (2013) recognized eight general types: Apology, Appreciation, Explanation, Please come back, Passive Follow-up, Correction, Active Follow-up and Compensation. Among them, Appreciation, Apology and Explanation were often used in the response of highly rated hotels, while Compensation was rarely mentioned by any hotel. Sparks \& Bradley (2017) developed a "Triple A" typology of management responses to negative online hotel reviews from 150 conversations in Tripadvisor, one of the world's most popular travel websites. The first category was "Acknowledgement", through which the hotel recognized, accepted or confirmed the problems raised by customers; the second one was "Account", through which the hotel explained to customers what happened and why that happened; the third was "Action", through which the hotel took action to solve problems.

Adopting the framework of rapport management, Feng \& Ren (2019) identified 14 relational acts in 220 Chinese management responses to consumer reviews from two famous Chinese online sales platforms: Taobao and Jingdong. In the order of descending in frequency, they were Thanking, Justification, Promising, Expectation of Future Purchase, Offer of Solution, Advertisement of Service/Products, Recommendation to Contact Customer Service, Unified Reply, Apology, Acknowledgement, Small Talks, Comforting Consumers, Self-Denigration and Request for Further Details. It was also found that reviews valence made a great difference in both types and frequency of the relational acts used. Drawing upon the concept of move structure (Swales, 1981), Zhang \& Vásquez (2014) took a deep analysis of 80 online negative review responses from 4- and 5-star hotels in four Chinese tourist destinations. Total ten moves were discerned: Express Gratitude, Apology for Sources of Trouble, Invitation for a Second Visit, Opening Pleasantries, Proof of Action, Acknowledge Complaints/Feedback, Refer to Customer Reviews, Closing Pleasantries, Avoidance of Recurring Problems and Solicit Response.

Combining rapport management with move structure, Ho (2017a, 2017b, 2018) identified relative moves in online hotel review responses. Eight moves were found in the responses by 205 -star hotels in five popular Asian cities, that is, Acknowledging Problem, Continuing Relationship, Denying Problem, Expressing Feeling, Greeting, Recognizing Reviewer's Value, Self-Promoting and Thanking Reviewer (Ho, 2017a). Three obligatory ones among them were Acknowledging Problem, Expressing Feeling and Thanking Reviewer. In Ho's another 2017's article, he gathered together 95 online responses in hotels based in Beijing, and distinguished two "mega moves", the Deny Problem Move and the Manage Rapport Move (2017b). Six sub-moves were grouped under the former: Challenge Reviewer's Decision, Frame Problem as Isolated Incident, Rebut, Suggest or Recommend, Highlight Facility or Service, and Emphasize Practice or Mission. Simultaneously, there were seven sub-moves in the category of the Manage Rapport Move with the purpose of making amends: Acknowledge Problem, Rectify Problem, Apologize, Explain Cause of Problem, Show Appreciation, Express Feelings, and Minimize Imposition. Later, Ho (2018) distributed questionnaires on the reviewers' opinion about the effectiveness of the hotel management's response, and obtained eight moves from 60 responses of them: Acknowledge Problem, Continuing Relationship, Denying Problem, Expressing Feelings, Recognizing Reviewer's/Comment's Value, Self-promoting and Thanking Reviewer. As was shown, findings in Ho's three successive researches from 2017 to 2018 kept highly consistent with each other, thus verifying the appropriateness and inclusiveness of these moves.

One common issue shared by the studies reported above is the choice of review response genre in CMC, and most of them drew the data from tourism or hotel accommodation industry. To bridge this gap, this present study diverts its attention to the customer hotline service in the airline industry, and gleans and transcribes the first-hand recordings of outbound calls to customer complaints. The complaint hotline is a popular channel for customers to 
make complaints and for agents to deal with them. It permits both interlocutors to communicate only orally in real time, unlike the written communication where people can get a moment to organize their thoughts and language. This character makes dialogues more direct, intense and genuine, and thus makes it more difficult to respond to customer complaints instantly. Furthermore, because the agents in the airline industry are very likely to encounter foreign passengers, the inaccurate or non-fluent speaking of target language, especially English, may also damage the rapport with customers. Different factors have increased the difficulty of managing the complaints in airline outbound calls, so the effective response strategies are worth exploring, which the agents need urgently for guideline.

Otherwise, few studies have researched on complaint itself before, but the truth is, the more we researchers interpret and understand the complaints, the more we will know how to respond appropriately and accurately. Thus, the authors will go further to summarize and analyze the major type of complaints. And this article will adopt theoretical framework of rapport management suggested by Spencer-Oatey (2008), Feng \& Ren (2019) and Ho (2017a, 2017b, 2018), and conclude the response strategies to the customer complaints, drawing upon the existing structure and criteria. It attempts to answer the three research questions:

1) What kinds of complaints do the customers make?

2) What response strategies do the agents use?

3) What are the effects of different strategies on rapport management?

\section{Methodology}

\subsection{Data Description and Collection}

The data was majorly collected from the outbound calls in customer complaint department in a well-known Chinese airline company. Its customer complaint department usually receives the different kinds of complaints that customers first send through E-mails, and then carefully deals with the complaints with the help of other sectors like system, security or accounting department. Later, the agents should make outbound calls to customers, in which they respond to explain about the present situation and progress of solving problems. The calls will be fully recorded. The major purpose is to reach the reconciliation between the customers and the company, to regain the customers' trust and to restore the company's image. Therefore, a successful and effective outbound call should take rapport and rapport management between customers and agents into good consideration.

The airline outbound calls were collected from a two-year cooperation project between the authors' university and the concerned airline company, conducted by the corresponding author. In this project, with written authorization and legal procedure, the company will selectively provide the researchers with some recordings of the outbound calls to customers from time to time. And then, the researchers in the university can glean them for the further transcription and analysis. The customers and agents in the recording materials talked mainly in English, while occasionally in Chinese. The finished four groups of transcription have more than 87 thousand words. Apart from collecting the call recordings, the researchers have also interviewed nine agents from the company, who were responsible for making outbound calls to customers. They were asked about work seniority, workflow, emergent issues, emotional management, attitude and method of response, etc. These dialogues were also recorded and transcribed in Chinese. Therefore, this article will explore both types of data: the airline outbound calls and the supplementary interviews.

\subsection{Data Analysis}

The authors will use a qualitative method with a conversational analytical approach to take a further analysis of the call transcription.

First, select out the customer complaints. The customers' remarks including rapport-threatening behavior should be extracted as customer complaints. That means, if some words of the customers are thought to have threaten the face, sociality rights and obligations, or interactional goals of the agents or the company, they will stand out as customer complaints.

Second, identify the type of customer complaints. The complaints will be classified based on their content, in which the customers may express the angry attitude, tell the disappointing fact or ask for compensation. Different content will determine the different type of complaints.

Third, summarize the response strategies. The customer complaints are always followed by the responses, where the agents may apply some strategies to manage the rapport with customers. For instance, they will try to calm down the angry customers, offer satisfactory solutions or even deny the charges for a good reputation. These are all important references to the specific response strategies. 
Finally, evaluate the effect of the strategies. According to the customer's reflection on the response, the strategies used will be estimated as rapport enhancement, maintenance, neglect or challenge. Specifically, if the customer shows obvious joy and gratitude to the agent, the strategy can be regarded as rapport enhancement; if the customer accepts the agent's solution or gets their emotion controlled, the strategy seems to maintain the rapport; when the customer keeps criticizing or just ignores the reply, we can say the rapport is neglected despite the use of strategy; and in the case that the customer gets infuriated by the response, or even gives rebuttals and criticism, the strategy will prove to challenge the rapport between both parties.

All in the four rounds of analysis, two coders (the authors themselves) will be involved to study the data independently. Both of them are Chinese native speakers and linguistic researchers. They will consult each other whenever they are uncertain about the coding, and discrepancies will be resolved through discussion. Due to the confidentiality requirement, the real name of the company appearing in examples will be replaced by XX.

\section{Findings and Discussion}

\subsection{Types of Complaints}

From the 55 records in the four groups of transcription, two coders extracted 120 relative dialogues about customer complaints, and identified the three general types of venting, requiring and stating. Venting means that customers made their complaints basically by venting their emotions like anger, disappointment or hatred. Requiring refers to the customers' requests or questions for the agents in their complaints. Stating shows that customers would tell the fact or truth calmly and seriously, in order to express their dissatisfaction and reproach.

Table 2. Types of complaints

\begin{tabular}{ccccc}
\hline Type & Venting & Requiring & Stating & Total \\
\hline Frequency & 68 & 39 & 31 & 138 \\
\hline
\end{tabular}

In Table 2, we can see that in the 138 pieces of customer complaints, the number of venting, requiring and stating is respectively 68,39 and 31 . Because the total number is obviously over the number of dialogues (120), some dialogues must simultaneously use two or three types of complaints. The frequency of complains using venting is about twice than those using requiring or stating. Specifically, the conclusion can be drawn that almost half of the customers tended to bring up feelings in the complaints, while over $1 / 4$ preferred directly asking questions or making requests, and the rest $1 / 4$ would state the truth to the agents instead. The following examples would illustrate the use of the three types:

\section{Example 1.}

Customer: Sorry. [I'll be emailing.] Because it's not about what we come today. It's a fault about XX account. It misuses the information. And it's unacceptable for an international company. So we'll be emailing now.

\section{Example 2.}

Customer: I'm so sad. I need to go back home and I need to take my medication. I need to fulfill my responsibility. Can you understand me?

\section{Example 3.}

Customer: I $<<\mathrm{f}>$ would find, I would personally find the e-mail address for the head of the office. I would find it online, and I'll send an e-mail directly to the head of the office, or I am walking to supervisor in cha:rge of this case, and then I'll be (???) off.

The underlined sentences in the above three examples show the customers' use of venting emotion. In Example 1, the customer put the blame and criticism on the airline company, threatening the company's face and image. In Example 2, the customer kept expressing the sadness and helplessness, but talking too much about personal things in some degree threatened the agent's association rights, for the relationship was not that close between the two parties. In Example 3, because the customer was irritated by the fact that the agent refused to give the supervisor's personal information, he/she blew off steam by threatening with cyber manhunt and harassment. This didn't meet the agent's interactional goal of trouble avoidance and relationship maintenance.

\section{Example 4.}

Customer: The security guard to be investigated, I think, should be fired. 


\section{Example 5.}

Customer: You're not even a manager?

\section{Example 6.}

Customer: I would like your manager's. The first (???) who is in charge of the complaint department. Manager of the Complain Department, I would like their name and ID number, please.

Example 4, 5 and 6 all show the use of requiring in the complaints. The customer in Example 4 directly requested the company to investigate and fire the security guard, and the force in the attitude threatened the company's equity rights. In Example 5, the customer asked the agent about the job position, and the tone of questioning threatened the agent's face. Then, the customer in Example 6 wanted to get the manager's name and ID number, and this slightly inordinate demand had threatened the agent's equity rights.

\section{Example 7.}

Customer: It's not that. I'm telling you as a customer, when you want to make a complaint, when you listen to the selection, it's not very clear.

\section{Example 8.}

Customer: In fact, my old brother used to say, when you spoke English Charles, because I spoke such simple English, I got to have it speaking simple English. So non-native English speakers could understand what to do more clear, easier.

\section{Example 9.}

Customer: Why not (???) You guys lost my bag. I didn’t complain.

In Example 7, the customer used stating to make complaints instead of venting or requiring. The problem was pointed out that it's not very clear in the customer complaint hotline, which threatened the company's face. The customer in Example 8 kept talking about his/her brother's words, and this kind of lengthy, wordy statement might wear the agent out of patience and threaten the association rights. Finally, in Example 9, the customer stated the fact that the airline company had lost his/her bag, thus obviously threatening the company's face and image.

\subsection{Response Strategies}

Facing the customer complaints, the two coders summarized three general types of response strategy and their subcategories. The details are as follows:

Table 3. Type of response strategies

\begin{tabular}{lll}
\hline Response strategies & Frequency & \multicolumn{1}{c}{ Sub-category } \\
\hline Soothing & 107 & apology, obedience, self-criticism, explanation, consolation, \\
Solution & 22 & sympathy, promise, gratitude, persuasion, avoidance \\
Challenge & 28 & suggestion, compensation, avoidance, reply \\
\hline
\end{tabular}

Concerning the theoretical background of rapport management, soothing can save face for both parties and maintain the rapport; the strategy of solution, which goes a step further to help customers, should enhance or maintain the relationship in an ideal situation; as for challenge, it will damage the rapport to a great extent, against the agent's willingness. The subdivision of different sub-categories is inspired by the classification of previous researches (e.g., Levy et al., 2013; Zhang \& Vásquez, 2014; Feng \& Ren, 2019).

According to Table 3, the most frequently used response strategy is soothing, correlated with the fact that most customers made complaints through venting. When customers cannot control their feelings, getting excited or emotional, it's the responsibility of agents to calm them down. The more specific responses include apology, obedience, explanation, self-criticism, consolation, sympathy, promise, gratitude, persuasion, avoidance and so on. Another strategy is solution, which means the agents will offer suggestions, compensations, avoidance or replies to answer customers' questions and solve their problems. In this view, the strategy of solution can be matched with requiring, the second type of complaints. The final strategy is to challenge customers when they make unreasonable requests or lose total control of their temper. In such cases, the agents have no other way but to show their rebuttal, refusal, avoidance or irony. From this point of view, challenge is majorly aimed at the inappropriate venting and requiring. According to their frequency, the three response strategies can be used separately or together. 


\subsubsection{Soothing}

\section{Example 10.}

Customer: So [why you] speak to the customer and I mean XX was disgraceful.

Agent: Okay. We feel really sorry for that, and we will apologize.

Customer: So what are you going to do about it?

\section{Example 11.}

Customer: Eh, do you mean. what kind of bank? I don't understand that yet. I just want you to get my money back.

Agent: Yes. I got it. But the money we will get back today. We will refund it today.

Customer: [When?]

\section{Example 12.}

Customer: I tried calling three times, nobody pick up the phone. And actually hang up on me three times.

Agent: Yeah. I'm sorry. Madam. But your ticket is a connection flight ticket, and then we can't make the application after any transfer. Because it's just.

Customer: Pardon.

These three examples show the strategy of soothing respectively in the case of venting, requiring and stating. In Example 10, the customer made bad comments on the airline company to vent the anger and dissatisfaction. Here the agent first said "Okay" as a manifestation of obedience, and then continued to apologize for the present situation. The agent tried to soothe the customer this way. In Example 11, the customer was requiring some answer and action from the company. If just focusing on the selected dialogues, some will doubt whether or not it can be regarded as a complaint. Considering the context before, the agent had been explaining the situation all the time, but the customer still could not get the idea. So the repeated question and request actually threatened the agent's transactional goal of communication, which can be seen as a complaint. For this, the agent had to give further explanation and promise to conciliate the customer, as the underlined sentences showed. Next, the customer in Example 12 stated the fact that nobody answered the phone for three times, gently questioning the company's attitude and ability. To alleviate the tension, the agent gave the apology and explanation. These replies involve various types of soothing.

From all the three examples above, we can see that although the strategy of soothing is majorly used for customers' venting emotions, it can also be applied in the complaints of requiring and stating. It's the most popular response strategy that targets all the three types of complaints.

\subsubsection{Solution}

\section{Example 13.}

Customer: Four bags, right?

Agent: Yeah, refund one, buy two (.) together.

Customer: That's what I want ((laugh)) [Yeah.] That's what I want.

\section{Example 14.}

Customer: The fail was because of the uselessness of the (???). You know not working properly.

Agent: Okay. So now you hope our staff help you to have a free selection of the plane. So how about that I will made an application for do that? So you hope us all the passengers to (sit) together.

Customer: So could you repeat that, please?

\section{Example 15.}

Customer: It has not been refund. I checked my credit card today. There was not refund yet.

Agent: [Okay.] And I will help you check about this refunding. And second_

Customer: Could you please check? yes.

Here in Example 13, 14 and 15, the agents offered solutions in response to the three types of customer complaints. The customer in Example 13 asked, "Four bags, right?" The reason why this question could be treated as a complaint is that the customer actually interrupted the agent before, threatening the latter's face and association rights. Although interjected by the requiring, the agent still replied the question patiently. Second, the customer in 
Example 14 was very discontent with the existing problem and leaked this feeling out, evidently threatening the company's face. The agent understood what the customer wanted and gave a practical solution within the capability in order to cool the temper. Third, in Example 15, the customer implied the company's incapability by describing what happened, and this complaint of stating would impair the company's face and image. To deal with it, the agent actively and immediately put forward a solution in reply, hoping for the rapport maintenance.

Just like the first strategy of soothing, solution can also be used to respond to all the three kinds of complaints, especially requiring. In fact, if there exist some problems, providing a solution is more essential and effective than just giving consolation. But in most cases, the agents have no ability or authority to bring out solutions suited both for the company and the customer. That's why the frequency of solution used is lower than that of the other two strategies, as Table 3 has shown. Usually, the agents are prone to make apologies, give promise and show gratitude instead of getting to the root of the trouble. But if they can resolve problems, solution is always the priority among the three response strategies.

\subsubsection{Challenge}

\section{Example 16.}

Customer: I know I'm right. (0.2) So you didn't know who pays your salary. The online supervisors don't know who pays their salary. (0.2) Something is wrong. And this is why you treat the customer?

Agent: We didn't treat the customer too bad, and we will offer..

Customer: [Wait]. Excuse me. Have you listened to the phone call that was made during lunch time last Thursday between me and Lily Feng and the (immediate?) telephone handler? Because the way you treated the customer there, you are-were (???)?

\section{Example 17.}

Customer: Can you get me to a manager, because I can't talk to you anymore.

Agent: No.

Customer: What? No? You can't get me to a manager? That was unbelievable.

As the authors mentioned before, challenge is the last strategy that the agents want to adopt, because it's very likely to damage the relationship with customers. In Example 16, the customer blamed the agent for the bad attitude and behavior and this threatened the agent's face. The latter felt wronged and unfair, so refuted the comment by saying "We didn't treat the customer too bad". Of course, this was a big challenge and provocation to the customer. And in Example 17, the customer made an unreasonable request for a manager's phone number. The agent, whose equity rights were threatened, straightforwardly rejected this demand with a single but powerful word "No". The customer was enraged by the challenging response as expected.

In the 120 extracted dialogues, the number of the strategy of challenge used is just 28 , and all of them are aimed at the complaints of venting and requiring. In other words, the agents understand the bad influence of challenge and try to avoid using it. When the customers tell some serious facts in a calm mood, there is no need for agents to reject or rebut violently, so they don't need to adopt this strategy against the complaint of stating.

\subsection{Effect of Strategies}

The effect of strategies will use the four rapport orientations as criteria. Based on the customers' reflection on the response strategies, the evaluation of rapport enhancement and maintenance could be thought as good effect, rapport neglect is almost equivalent to no effect, and rapport challenge means that the strategies have a bad effect on the agent-customer relationship, damaging the rapport between them. The details are as follows:

Table 4. Effect of strategies

\begin{tabular}{lllll}
\hline$F_{r_{e}}$ Strategy & soothing & solution & challenge & Total \\
\hline effect & & & & 2 \\
\hline $\begin{array}{l}\text { maintenance } \\
\text { neglect } \\
\text { challenge }\end{array}$ & 1 & 1 & 1 & 25 \\
\hline
\end{tabular}


Table 4 reveals the effect of the response strategies on rapport management. On the whole, almost half of the strategies neglected the rapport, making no direct or obvious difference to the relationship between agents and customers. About $23 \%$ even took adverse effect and challenged the relationship. On the other hand, 27 pieces of strategies out of the whole 92 proved to be effective; that is to say, more than $29 \%$ responses using strategies enhanced or maintained the rapport according to the statistics. Because some of the customer complaints were replied with more than one response strategy, in this case, the effect on rapport management should be a combined or synergistic result. But in this article, the authors want to focus only on the individual effect of every strategy, so it is based on this precondition that the numbers in Table 4 were counted. The joint effect of several response strategies is not taken into account here.

To further explain, let's look at the previous examples to check the effect of the three response strategies. First, in Example 10, the customer replied the agent with a question, "So what are you going to do about it?" This means that the customer accepted the agent's apology and expected a deeper discussion, proving that the strategy of soothing maintained the rapport. But in Example 12, the customer didn't catch what the agent said before, so the soothing strategy in response made no effect because of the bad signal. Second, the customer in Example 13 repeated "That's what I want" with a laugh, showing the satisfaction and gratitude for the agent's reply. The strategy of solution enhanced the rapport and thus had a good effect. The customer in Example 14 also suffered the signal problem and couldn't hear the agent's response clearly, so the solution here was ineffective. In Example 15 , the customer asked "Could you please check", and this indicated the agent's offering to check out the refunding was agreed and accepted. Surely, the effective solution maintained the rapport. Finally, there is almost no suspense in the effect of challenge. To challenge the customers' idea or comment is to challenge their face and the rapport with them, as Example 12 and 13 showed. This will usually have a terrible effect, especially when the strategy of challenge is used alone. But there was an exception in Table 4-one strategy of challenge surprisingly resulted in rapport maintenance with the customer. An educated guess is that this customer was sympathetic and empathetic enough to understand that the company had its own difficulty and rule. It's an unusual case.

As for the strategy of soothing, the number showed that less than $30 \%$ related responses were effective, namely, enhancing or maintaining the relationship. In addition, half of responses using solution turned out to take favorable effect on the agent-customer relationship, while another half either neglected or damaged the rapport between. In conclusion, both the total and individual effect of the three response strategies seemed not good or satisfying enough.

\subsection{Further Discussion}

To answer the first research question, three types of customer complaints are found including venting, requiring and stating, and venting emotions is the most popular one. For the second research question, there are three general types of strategies in response to the complaints: soothing, solution and challenge; the strategy of soothing is used much more frequently than the other two. Basically, the complaint of venting can be matched with the strategy of soothing, while requiring can be paired with solution. But it is not absolute or fixed. Soothing is commonly applied in all three types of complaints, because in any case, consolation and reassurance cannot be wrong if used politely and properly. Likewise, solution is not restricted within the range of requiring. If the agents can find what the customers really want behind their emotional words, direct requests or seemingly calm statements, and simultaneously, if the agents are able to meet these reasonable demands with the help of other different departments, offering solution must be the best strategy to handle customer complaints and should be considered first and foremost. However, in the real life, the agents must be careful and cautious enough to face customers and their complaints, trying to balance the customers' wants and the company's needs, so it's never been easy for them to make specific promise or offer immediate solutions. This is why the strategy of solution wasn't used frequently in the data. As for challenge, the agents always try to avoid it because of its bad influence on the rapport and relationship. When there is no better choice but to take a stand and maintain the company's principle, the agents usually use challenge together with the other two strategies in order to defuse the tension.

To answer the third research question, it was found that the overall effect of response strategies was dissatisfying. The number of responses achieving rapport enhancement and maintenance is clearly smaller than that causing rapport neglect and challenge. However, it doesn't mean the three strategies of soothing, solution and challenge are ineffective or useless, but instead they are meaningful tools for handling complaints. To clarify why the effect is not obvious needs to take both subjective and objective reasons into account. For instance, when people lose the control of their temper, it's hard to stop them from venting feelings violently, and sometimes, no matter what you said or even when you said nothing, they still could find an excuse to fire on you. This might explain why over $70 \%$ of responses applying the strategy of soothing were neglected or unaccepted by the customers. Moreover, in the case that the customers' requests are indeed unreasonable or unbelievable, the agents, on behalf of the company, 
have to stand firm to reject them, though this will probably irritate the customers again and further damage the rapport. Even if the agents provide as good solutions as possible at the time, the customers may still not be 100 percent content and find it perfunctory. This is correlated with the fact that half responses using the strategy of solution unexpectedly neglected or challenged the rapport in the statistics. And when there is a signal problem in the complaint hotline as Example 12 mentioned above, the customers cannot catch the clear idea, so the effect of communication will be affected.

Apart from that, one thing that should be noticed is that all the three response strategies in Table 3 share the same sub-category of avoidance. In Example 1, after the customer finished the bad comment on the airline company, the agent actually replied, "[You mean] that you will send after-email for further information?" Avoiding the customer's criticism and anger, this response changed the topic to the e-mail sending affair, and this was an application of soothing. Then the customer continued to say "I'll send an email in details about everything", from which we know the customer's attention was successfully diverted and the response maintained the rapport.

\section{Example 18.}

Customer: Am I speaking to someone who speak English correctly you know? I should speak to someone who speak English correctly because you can't understand what is speaking to you.

Agent: Hold on please.

Customer: Yeah. Thank you.

\section{Example 19.}

Customer: $\underline{I}$ don't want to issue any ticket any more. I will go to [book my ticket] on somewhere, reliable. (???)

Agent: So could you like to book another ticket by XX or

Customer: No! I told you I will turn to another one not XX.

Example 18 shows the use of avoidance as the sub-category of solution. Here, the customer required speaking to someone with good English-speaking skill, and the agent replied, "Hold on please." Although the latter avoided saying yes or no directly to the customer's request, the response could imply that the agent tried solving the problem and finding the right person for the customer. Therefore, the avoidance belonged to the category of solution, and because the customer showed the gratitude later, this strategy successfully maintained the relationship. In Example 19, the customer declared out of rage that he or she wouldn't choose this airline anymore, but the agent seemed to deliberately avoid the declaration and still asked the customer whether to book the ticket from this company. Ignoring the customer's desire and making the situation tenser, unfortunately, the use of avoidance could be seen as a provocation and should be included in the strategy of challenge. Regarding the effect, it obviously damaged the rapport with the customer. In brief, the use of avoidance can belong to any of the three response strategies, and may accordingly cause different effect.

From the transcription of interviews with correlative agents, we can see these agents are professional enough to deal with regular and special cases, to do the emotional management, and to gain experience and lessons. What they should improve lies on the specific details. In other words, since the response strategies are useful, the agents might be trained to use them more effectively and efficiently.

First, language is a very important issue. Not only should the agents speak English correctly and fluently, but they must master the specialized glossary and expressions about the airline service. The authors remembered that in the records of outbound calls, a customer kept criticizing the agent's spoken English, saying it's "really, really bad"; another customer misunderstood the agent's explanation and thus argued for a long time, just because the agent misused one professional word. Hence, to improve the English skills can help the agents reduce the chance of being accused, spend less time and energy in explaining and provide more efficient service. Moreover, the agents can do better in the emotional management. It was discerned that some agents occasionally revealed slightly impatient and intolerant feelings. If the authors as a third party can notice this, the customers involved are more likely to discover the negative emotion and reproach the agents. Indeed, it's necessary for them to manage emotion and feelings more professionally.

\section{Conclusion}

Customer complaints can have a significant influence on the rapport and relationship between customers and companies. With the guidance of rapport management, this study majorly collected its data from the airline outbound calls, and aimed to classify the customer complaints, investigate the specific types of response strategies and evaluate the effect of strategies used. After the analysis, the findings identified three kinds of complaints including venting, requiring and stating, and summarized another three types of response strategies comprising 
soothing, solution and challenge. The effect of these strategies on rapport management proved to be mediocre or unobvious.

The present study has made both theoretical and practical contributions. Theoretically, it explored complaints themselves deeper than previous researches, specifically discussing the content and type. Moreover, the authors used the first-hand recording materials of outbound calls, from a new airline industry instead of the frequentlychosen areas like hospitality and tourism. Practically, this article can offer suggestions based on findings to help agents in the company manage customer complaints better, through appropriate response strategies and communication skills. These can provide some inspirations for other researchers with interest.

However, there still exist some limitations in this study. First, the data size may not be large enough for the quantitative analysis and the more accurate qualitative analysis. Second, the interview data could be investigated more deeply and thoroughly in the future, and it can be collected through not only sound recordings but also video recordings. Third, apart from the calls and interviews, other types of data wait to be chosen and researched for a more effective triangulation analysis and validation. Finally, the transcription of recordings may be further modified and standardized to be more specific and detailed, so the tone and intonation of interlocutors can be uncovered for the deeper discussion.

\section{References}

Brown, P., \& Levinson, S. (1987). Politeness: Some Universals in Language Usage. Cambridge: Cambridge University Press.

Feng, W., \& Ren, W. (2019). "This is the destiny, darling": Relational acts in Chinese management responses to online consumer reviews. Discourse Context Media, 28, 52-59. https://doi.org/10.1016/j.dcm.2018.09.003

Goffman, E. (1955). On face-work: An analysis of ritual elements in social interaction. Psychiatry: Journal for the Study of Interpersonal Processes, 18, 213-231. https://doi.org/10.1080/00332747.1955.11023008

Ho, V. (2017a). Achieving service recovery through responding to negative online reviews. Discourse Commun, 11 (1), 31-50. https://doi.org/10.1177\%2F1750481316683292

Ho, V. (2017b). Giving offence and making amends: how hotel management attempts to manage rapport with dissatisfied customers. Journal of Pragmatics, 109, 1-11. https://doi.org/10.1016/j.pragma.2016.12.001

Ho, V. (2018). Exploring the effectiveness of hotel management's responses to negative online comments. Lingua, 216, 47-63. https://doi.org/10.1016/j.lingua.2018.10.004

Javornik, A., Filieri, R., \& Gumann, R. (2020). “Don't Forget that Others Are Watching, Too!” The Effect of Conversational Human Voice and Reply Length on Observers' Perceptions of Complaint Handling in Social Media. Journal of Interactive Marketing, 50, 100-119. https://doi.org/10.1016/j.intmar.2020.02.002

Lee, Y. L., \& Song, S. (2010). An Empirical Investigation of Electronic Word-of-Mouth: Informational Motive and Corporate Response Strategy. Computers in Human Behavior, 26(5), 1073-1080. https://doi.org/10.1016/j.chb.2010.03.009

Levy, S., Duan, W., \& Boo, S. (2013). An analysis of one-star online reviews and responses in the Washington, D.C., lodging market. Cornell Hospitality Quarterly, 54(1), 49-63. https://doi.org/10.1177\%2F1938965512464513

Phau, I., \& Puspita Sari, R. (2004). Engaging in complaint behaviour: An Indonesian perspective. Marketing Intelligence \& Planning, 22(4), 407-426. https://doi.org/10.1108/02634500410542770

Singh, J., \& Widing, R. (1991). What Occurs Once Consumers Complain? A Theoretical Model for Understanding Satisfaction/ Dissatisfaction Outcomes of Complaint Responses. European Journal of Marketing, 25(5), 3046. https://doi.org/10.1108/03090569110140489

Sparks, B., \& Bradley, G. (2017). A 'triple A' typology of responding to negative consumer generated online

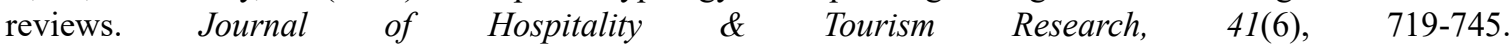
https://doi.org/10.1177\%2F1096348014538052

Spencer-Oatey, H. (ed.). (2008). Culturally Speaking: Culture, Communication and Politeness Theory (2nd ed.). London: Continuum.

Swales, J. (1981). Aspects of Article Introductions. Birmingham, AL: University of Aston.

Van Noort, G., \& Willemsen, L. M. (2012). Online damage control: The effects of proactive versus reactive webcare interventions in consumer-generated and brand-generated platforms. Journal of Interactive 
Marketing, 26(3), 131-140. https://doi.org/10.1016/j.intmar.2011.07.001

Zhang, Y., \& Vásquez, C. (2014). Hotels’ responses to online reviews: Managing consumer dissatisfaction. Discourse, Context and Media, (6), 54-64. https://doi.org/10.1016/j.dcm.2014.08.004

\section{Copyrights}

Copyright for this article is retained by the author(s), with first publication rights granted to the journal.

This is an open-access article distributed under the terms and conditions of the Creative Commons Attribution license (http://creativecommons.org/licenses/by/4.0/). 